\title{
Development of a Behaviorally Induced System Optimal Travel Demand Management System
}

\author{
Xianbiao $\mathrm{Hu}^{1 *}$, Yi-Chang Chii ${ }^{2}$, Jeff Shelton ${ }^{3}$ \\ ${ }^{1 *}$ Department of Civil Engineering and Engineering Mechanics, University of Arizona, Tucson, \\ AZ, xbhu@email.arizona.edu \\ ${ }^{2}$ Department of Civil Engineering and Engineering Mechanics, University of Arizona, Tucson, \\ $A Z$ \\ ${ }^{3}$ Texas A\&M Transportation Institute, El Paso, TX
}




\begin{abstract}
The basic design concept of most Advanced Traveler Information Systems (ATIS) is to present generic information to travelers, leaving travelers to react to the information their own way. This “passive” way of managing traffic by providing generic traffic information makes it difficult to predict outcome and may even incur adverse effect, such as overreaction (a.k.a. the herding effect). On the contrary, Active Traffic and Demand Management (ATDM) is another approach that has been receiving continual attention from both academic research and real-world practice, aiming to effectively influence people’s travel demand, provide more travel options, coordinate between travelers, and reduce the need for travel.

The research interest discussed in this paper is how to provide users with a travel option that aims to minimize the marginal system impact that results from this routing. The goal of this research is to take better advantage of the available real time traffic information provided by ATIS, further improve the system level traffic condition from User Equilibrium (UE), or a real world traffic system which is worse than UE, towards System Optimal (SO), and avoid passively managing traffic which may incur adverse effect. A behaviorally-induced, system optimal travel demand management model is presented to achieve this goal through incremental routing. Both analytical derivation and numerical analysis have been conducted on Tucson network, AZ, as well as Capital Area Metropolitan Planning Organization (CAMPO) network in Austin, TX. The outcome of both studies show that our proposed modelling framework is promising for improving network traffic conditions towards SO, and results in a vast amount of economic savings.
\end{abstract}


Keywords: Travel Demand Management (TDM), System Optimal, Travel Behavior, Behaviorally Induced System Optimal, Active Traffic and Demand Management (ATDM), Dynamic Traffic Assignment 


\section{INTRODUCTION}

Traffic congestion imposes a tremendous burden on society as a whole. For decades, the most widely applied remedy has been building more roads to better accommodate traffic demand, which turns out to be of limited effect: infrastructure construction and maintenance are very costly, and as more demand is induced, that added demand quickly saturates the newly built highways. Travel Demand Management (TDM), and recently Active Traffic and Demand Management (ATDM) is another approach that has been receiving continual attention from both academic research and real-world practice, aiming to effectively influence people's travel demand, provide more travel options, and reduce the need for travel. A variety of TDM programs have been applied in real world practice, such as flexible work hours, teleworking, vanpooling, ridesharing, transit, etc.

Real-Time Traveler Information Systems or ATIS provide pre-trip and/or enroute information allowing travelers to quickly assess and react to unfolding traffic conditions. The basic design concept is to present generic information to travellers, leaving travelers to react to the information their own way. This "passive" way of managing traffic by providing generic traffic information makes it difficult to predict outcome and may even incur adverse effect, such as overreaction, which may lead to herding effects. Here, herding effects, or sometimes refers to "herd behavior", describes how individuals in a group can act collectively without centralized direction. To be specific, if a particular road segment is identified to be free flowing, ATIS will recommend this route to every driver around. If they all follow the navigation device, after a while, this road segment will become congested, and drivers may find themselves stuck in traffic and sitting in the long queue again. 
For those ATIS that come with path finding functionality, the goal is often to provide users with the path with lowest instantaneous travel time (cost) without explicitly considering the marginal impact of this routing action and even of many others following similar requests. The research interest in this paper is how to provide users with a route that aims to minimize the marginal system impact that results from this routing. In other words, when one makes a trip, the true Marginal Cost (MC) would include not only the one traveler's experienced travel time in the network, but also the delays this trip imposes upon other vehicles in the vicinity or departing afterward. The goal of this research is to take better advantage of the available real time traffic information provided by ATIS, further improve the system level traffic condition from User Equilibrium, or a real world traffic system which is worse than UE towards SO, and avoid passively managing traffic which may incur adverse effect such as herding effects.

In this paper, a behaviorally induced, system optimal travel demand management model is presented aiming to at the system level, further improve traffic condition towards System Optimal through incremental routing. The originality of this research is to consider System Optimal as the objective from the overall standpoint of the system as a whole, which distinguishes itself from most of the other ATIS or TDM researches that did not explicitly consider the marginal cost to the system when assigning multiple travelers to the system. In addition, the incremental routing mechanism designed in this model is able to avoid the commonly seen herding effects. Both analytical derivation and numerical analysis have been conducted on Tucson network, AZ, as well as Capital Area Metropolitan Planning Organization (CAMPO) network in Austin, TX. The outcome of these studies show that our proposed nonconstruction required modelling framework is promising for improving network traffic conditions towards SO, resulting in a vast amount of economic savings. 
This paper is organized as follows. Section 2 reviews the relevant past literature. Section 3 discusses the modelling framework and approach in detail, and Section 4 presents the case study results using the Dynamic Traffic Assignment (DTA) modelling platform DynusT on Tucson and CAMPO networks. Section 5 concludes this research.

\section{LITERATURE REVIEW}

Almost all ATIS platforms or other ITS applications are built based on UE (Toledo and Beinhaker 2006; Bifulco, Cantarella et al. 2014; Karimi and Asavasuthirakul 2014; Antoniou, Polydoropoulou et al. 2015; Liao and Chen 2015; Tsirimpa 2015), which assumes all the drivers have perfect information about traffic conditions and make the optimal decision independently based on their own interests. In contrast, SO requires a system to have control over all vehicles' routing decisions and to make decisions to minimize the system total travel time as a whole, which makes it more difficult to implement.

Dynamic network loading is an important research topic in the DTA area, and various approaches have been proposed to model traffic dynamics, such as link-based travel time functions, where link traffic dynamics are captured using a continuous time link mode, and each link is usually modeled with two segments, i.e. a running segment and a queuing segment (Friesz, Bernstein et al. 1993; Castillo, Nogal et al. 2013; Zheng and Van Zuylen 2014); celltransmission mode, where each arc is discretized into a series of cells, and the arc attributes are a trapezoidal flow-density function, and a flow control mechanism such as stop sign, or signalcontrolled (Daganzo 1994; Lee 1996; Mesa-Arango and Ukkusuri 2014); discrete-flow model, which is based on the car-following relationship that can be solved by a link-based algorithm (Mahut 1999; Mahut 2001), and so on. 
A rather wide and diversified body of research about Marginal Cost exists in the literature, studying various aspects including theory, calculation, application, etc. In fact, research on Marginal Cost exists in several research areas, such as Congestion Pricing and SODTA, Transportation Policy and Decision Making, e.g., consideration of a Vehicle Miles Traveled (VMT) Tax. Depending upon the research objective, these Marginal Cost-related research efforts could be generally classified into two categories: 1) External Marginal Cost and 2) Marginal cost in terms of travel time.

External Marginal Cost usually refers to the various externalities the traveler brings to the existing network, such as the congestion, infrastructure deterioration, emissions, safety impacts and so on (Mayeres, Ochelen et al. 1996; Wismans, Berkum et al. 2013). The marginal cost research in this category usually tries to translate those external costs to be stated and understood in terms of monetary value in order to assist in real world decision making. Marginal Cost research in the second category usually looks into the marginal travel time contribution of an additional unit of flow into the system. Ghali and Smith (1992) defined four levels of Marginal Cost from the perspective of queuing delays. The first level is the travel time on that link that an additional driver experiences; the second level includes the additional delay experienced by all vehicles that traverse that link after that vehicle. The third level extends the definition of the second level to include the additional delay to all vehicles (on all links) whose path travel times are increased due to that vehicle, and the fourth level defines the global link, marginal travel time brought about by that additional vehicle. Peeta (1994) also has a similar definition for marginal travel time in this category from several perspectives: 1) static or time-dependent, 2) global or local, and 3) link-level or path-level. 
Various studies can be found on Marginal Cost with respect to the second category, especially in the area of congestion pricing and SO-DTA. To name a few: Sheffi (1985) calculated the marginal travel time cost caused by the additional traveler on Ghali and Smith's first and second level, but the link interactions were ignored in his static system optimal assignment problem. Shen et al. (2007) demonstrated by analyzing a series of examples that path marginal costs are not simply the summation of the corresponding link marginal costs, unless the flow perturbation travels with the vehicle unit that initiated the perturbation. Qian and Zhang (2011) proposed a method to compute the total path marginal cost in a network with a celltransmission-model-based (CTM-based) kinematic wave model, which they used to model traffic dynamics by tracing the changes in the cumulative flow curves of the bottleneck links on which queues form. Alibabai and Mahmassani (2012) built a model to evaluate marginal cost that can guide the search for system optimal traffic strategies. Research on marginal cost in this category

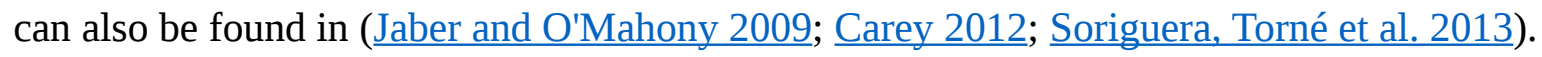

One important, noteworthy aspect of real-world application of the SO concept is the partial compliance with the SO principle, as opposed to the assumption of full compliance (Gazis 1995; Kachroo and Özbay 2006; Meng and Khoo 2008; Zhang and Chang 2014). Not all users have access to SO information and also not all are able to, or willing to, comply with the SO principle, as suggested in ( $\mathrm{Ng}$ and Sathasivan 2014; Liao and Chen 2015) which studied the traveler's response to traffic information provided. While assuming all users are SO compliant is unrealistic, one can still exploit the opportunity to have only a fraction of total drivers be SO compliant, if they are motivated to do so. This research aims to exploit such opportunity and investigate the degree of overall system improvement that can be achieved due to such behaviorally induced drivers following routes that are computed based on the SO principle. Most 
preceding research also assumed fixed demand, limiting the choice dimension only to route but not departure time. This research also aims to relax this limitation and explore both route and departure as dimensions of the SO management decision.

\section{METHODOLOGY}

\subsection{Overall Research framework}

This research proposes a behaviorally induced DTA model that is capable of further improve the system level traffic condition from User Equilibrium, or a real world traffic system which is worse than UE, towards SO. The framework of this research is illustrated in Figure 1. The major body of this work flow is the iteration included in the blue box, with the major components listed below:

1 Marginal Cost calculation / update, i.e. compute and update the marginal cost of adding one additional vehicle with specific departure time and route choice into traffic network.

2 Time-Dependent Shortest Path (TDSP) search, i.e. solve shortest path problem within a timedependent traffic network.

3 Schedule Delay (SD) calculation, i.e. compute the penalty associated with specific schedule, either due to arriving at destination later than expected, or earlier than expected.

4 Optimal path finding, i.e. find the best departure time choice and route choice that minimizes the overall travel cost.

5 Link flow update, i.e. update the traffic volume of a particular road segment after assigning a vehicle to the network. 
As illustrated in Figure 1, the general idea of this algorithm is that, first of all, finds the optimal travel choice, i.e. departure time choice and route choice for an individual driver, by considering the marginal cost of each travel choice, schedule delay cost, and performing Shortest Path search ${ }^{1}$. Next, after determining the optimal travel choice for this vehicle, the traffic volume for each link of interest will be updated, together with their marginal cost. Then, the algorithm will continue to find the optimal travel choice for the next vehicle, following the same procedure defined previously. The search for optimal travel choice, i.e. incremental routing strategy will keep going until every vehicle has been found the best travel option. Finally, we will run DTA simulation to simulate the scenario and generate the new total system travel cost, and perform analysis based on that.

It should be noted that, in reality, the real system built based on this research merely "shows" multiple choices (in terms of departure time and route) together with their associated costs and incentives to the users, with the goal of facilitating the decision making process and influencing their travel behavior, but does not "determine” which option should the user choose. If the user browses to the departure time slots during AM or PM peak hours, the travel time could be high, and if he/she browses to the time slots in non-peak hours, the travel time would be much lower. The system encourages user to make an informed decision that is better, or at least no worse than his/her habitual behavior, and as long as certain (even small) percentage of users can make informed decisions, the traffic condition can be improved.

1 In the real world, acquiring the latest traffic condition could be challenging but is the perquisite of the routing. When the real world ATDM system "Metropia" was built (www.metropia.com), we firstly relied on the multi-source traffic data, including loop sensors, GPS devices, cell phones signals, which can cover approximately more than half of the main roads, namely, freeways, highways, and arterial links. Then, an "imputation" algorithm was developed to "guess" the traffic condition for the links without any data. Such "imputation" algorithm was based on network topology and traffic flow characteristics. Lastly, the real user trajectory from our smartphone app "Metropia" was collected and processed in a real time fashion, so the app users essentially become the "GPS probe vehicles". 


\subsection{Marginal Cost calculation}

In this research, the volume-delay function (Roads 1964) is used to establish the relations

between traffic demand and travel time, see Eq. (1), where both traffic demand $v_{i j t}$ and travel

time $S_{i j t}\left(v_{i j t}\right)$ for link $(i, j)$ are time dependent.

$$
S_{i j t}\left(v_{i j t}\right)=t_{i j}\left(1+\alpha\left(\frac{v_{i j t}}{C_{i j}}\right)^{\beta}\right)
$$

with

- $\quad t_{i j}$ : free flow travel time on link $(i, j)$

- $\quad v_{i j t}$ : traffic demand on link $(i, j)$ at timet

- $\quad C_{i j}$ : capacity of link $(i, j)$

- $S_{i j t}\left(v_{i j t}\right)$ : The average travel time for link $(i, j)$ at timet

- $\quad \alpha$ : coefficient

- $\beta$ : exponent. $\alpha$ and $\beta$ can be calibrated based on the speed-volume relationships from the DTA simulation model.

Based on the volume-delay function, the link marginal cost could be derived by taking

the derivative of $v_{i j t}$; see the following Eq. (2): 


$$
M C=\frac{\delta\left(v_{i j t} * S_{i j t}\left(v_{i j t}\right)\right)}{\delta v_{i j t}}=S_{i j t}\left(v_{i j t}\right)+\frac{v_{i j t} * \delta\left(S_{i j t}\left(v_{i j t}\right)\right)}{\delta v_{i j t}}=t_{i j}\left(1+\alpha\left(\frac{v_{i j t}}{C_{i j}}\right)^{\beta}\right)+\frac{t_{i j} * \alpha * v_{i j t} * \beta * \mid}{C_{i j}}
$$

The marginal cost calculated from Eq. (2) includes the travel time that the additional driver experiences on that link (the first part in Eq. (2)), and corresponds to the first level of marginal cost defined by Ghali and Smith (1992). The second part in Eq. (2) is the additional delay experienced by all vehicles that traverse that link after that vehicle, which corresponds to the second level of marginal cost in the same definition.

As illustrated in Figure 1, at the next step, TDSP will be sought for based upon link marginal cost, and the marginal cost on that local link will expand to affect the whole path of that vehicle. Then, assigning the optimal TDSP to each individual vehicle will lead to the changes of links volume along the path, and the marginal cost will need to be recalculated as well. In the end, every vehicle to be assigned in the network at a time later than that previous vehicle will be affected. With this procedure, the marginal cost of this particular user will be expanded to affect all other vehicles of interests at the global network level, which corresponds to the third and fourth levels of marginal cost as defined by Ghali and Smith (1992).

It should be noted that the purpose of applying extended-BPR function in this research is quite different from that of dynamic network loading models. In fact, after calibrating the demand and shifting it from both temporal-wise and spatial-wise with BPR function, the real DNL model embedded in DynusT DTA model i.e. Anisotropic Mesoscopic Simulation (AMS) model (Chiu, Zhou et al. 2009) was used for the network loading purpose to perform traffic simulation and determine the system benefits of the proposed model in this research. The literature review section has demonstrated that there're plenty of existing marginal cost related researches out there, and the computation method could get very complex. But building another 
highly sophisticated model to accurately calibrate the marginal cost is not the focus, nor expected to be the original contribution of this paper. Instead, a formulation that can links "demand" and traffic condition, enables the cost comparison between different travel options, implementable and computational efficient for a large size network is desired and adopted.

\subsection{TDSP algorithm}

A revised Time-Dependent A* algorithm is developed to search for a TDSP for each experiment vehicle. For this algorithm, its uniqueness lies in that the time-dependent marginal cost is used as the link travel cost when searching for the shortest path, which makes the algorithm different from the standard A* search algorithm. Three major modifications are listed below :

Modification 1: Each link will keep two cost values at the same time; the first one is the

travel time cost denoted as $t t_{i j}$, another one is marginal cost value denoted as $m c_{i j}$ which is computed from section 3.2.

Modification 2: The link marginal cost derived by Eq. (2) is used as link cost in the TDSP

algorithm instead of the link travel time cost; i.e. it is the marginal cost of link $(i, j)$ traversing at time $T_{i}$ (denoted as $m c_{i j}\left[\tau\left(T_{i}\right)\right]$ ) that is used as link cost, instead of the link travel time $t t_{i j}\left[\tau\left(T_{i}\right)\right]$. Here, $\quad \tau\left(T_{i}\right)$ stands for departing node i at time $\quad T_{i}$. Modification 3: Each node will keep two different time stamps $\quad L_{i}$ and $T_{i}$. While $L_{i} \quad$ is used to record the upper bound of the minimum travel cost (which is marginal cost now) 
from origin to node $i, T_{i}$ is introduced to record the actual travel time cost from origin to node $i$.

\subsection{Schedule Delay}

Schedule delay (SD) is an attribute of a given scheduling choice which measures the deviation inherent in that choice between actual and preferred arrival time, where the deviation may be due either to early or late arrival. A variety of schedule delay formulations and parameter setting were

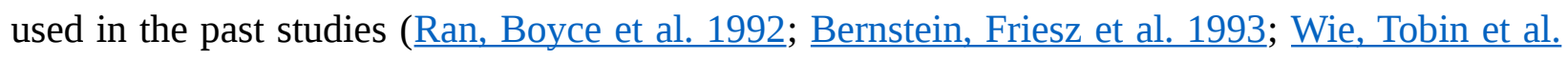
1995). A piecewise linear formulation was adopted in this research to represent the schedule delay cost for travelers with an ( $o, d, P A T$ ) triplet:

$$
\begin{gathered}
-i-t_{0}-T T \\
P A T^{i} \\
\dot{i} \\
-i>t_{0}+T T \\
+\dot{+} \\
+\dot{+} \\
t_{0}+T T-P A T^{i} \\
-i \leq t_{0}+T T \leq P A T^{i} \varphi_{2} * i \text { if } t_{0}+T T>P A T^{+i} \\
\dot{i} \\
\varphi_{1} * \dot{i} \\
S D=i
\end{gathered}
$$

Where:

$$
\text { ideal arrival time window is represented as } \begin{gathered}
-i, P A T^{i} \\
P A T^{i} \\
i
\end{gathered} \text {, with } \mathrm{PAT}^{-} \text {as the lower bound }
$$

for Preferred Arrival Time (PAT) at the destination without incurring schedule delay and $\mathrm{PAT}^{+}$ the upper bound 
$\varphi \quad$ is a parameter for measuring the gap between actual arrival time and PAT. $\varphi_{1}$

and $\varphi_{2}$ represent early and late cost parameters, respectively.

$t_{0}$ : departure time of the trip

$T T$ : travel time of the trip

\subsection{Optimal Path Finding}

Generally speaking, for the departure time and route choice problem, travel cost and arrival schedule delay are the two travel impedances considered by travelers. In other words, the problem of finding the optimal travel plan will in the end come down to the decision of finding

out the best departure time $t_{0}$ ' and route choice $r$ ' within the allowed departure time window, so that the total travel cost can be minimized.

If we follow the general trend and name this type of travel cost as general cost, containing cost from trip marginal cost MC as well as from arrival schedule delay SD, the generalized cost expression can be depicted as follow:

$$
G C_{t_{0}}=\mu * M C_{t_{0}}+S D_{t_{0}}
$$

Usually the parameter of travel time cost $\mu$ is intentionally set to be greater than $\varphi_{1}$

but less than $\varphi_{2}$, so as to prevent vehicles from needlessly spending more time in the network to avoid early penalties. 
As illustrated in Figure 1 and Section 3.1, the purpose of Optimal Path Finding is to find,

for each vehicle, the best departure time $t_{0}{ }^{\prime}$ and route choice $r^{\prime}$ within the allowed departure time window, so that the generalized cost can be minimized.

$$
G C_{t_{0}}^{r^{\prime}}=\operatorname{Min} G C_{t_{0}}^{r}
$$

It is worth noting that the schedule delay cannot be evaluated until the trip has been completed, by which time the trip arrival time will be available. In this research, departure time choices for each individual traveler are simulated with small incremental steps, i.e. 1 minute, within the allowed departure time window, and TDSP is sought for. The travel time and schedule delay will then be computed, and the one with the minimum general cost will be selected as the optimal departure time and route choice for the traveler.

\section{CASE STUDY}

\subsection{Case study 1 - Tucson I-10 network}

\subsubsection{Background}

The case study described in this section was conducted to illustrate the system performance and behavior changes of the proposed System Optimal model. We chose the Tucson I-10 network to be our case study region which consists of 395 nodes, 830 links and 80 traffic zones. Figure 2 shows the Tucson network in DynusT GUI (Chiu, Nava et al. 2011). 5 scenarios are designed in this section ${ }^{2}$ ( $\left.\underline{\mathrm{Hu} 2013}\right)$.

2 This case study was extracted from the author's dissertation, where in total 14 scenarios were modeled. Considering the length of paper to be published in a journal, the author only selected a few representative scenarios to demonstrate the capability of the proposed model and analyze the behavior changes from the drivers. 
- Baseline Scenario: In this research we use User Equilibrium flow, all other scenarios are derived from the baseline scenario dataset.

- Scenario 1 (SC1): Simulate the scenario that $10 \%$ of travelers are willing to change their travel behavior up to 15 minutes.

- Scenario 3 (SC3): $10 \%$ travelers willing to change departure time up to 60 minutes.

- Scenario 6 (SC6): 20\% travelers willing to change departure time up to 120 minutes.

- Scenario 7 (SC7): 30\% travelers willing to change departure time up to 120 minutes.

It should be noted that User Equilibrium does not necessarily only consider route choice, in fact, there have been a great number of works on UE with simultaneous departure-time and route choices. However, in this manuscript, the time-dependent O-D demand in the baseline scenario is assumed to have fixed temporal departure time pattern, i.e. the UE solution in baseline scenario only captures route choice, whereas changing departure-time will be allowed in the other scenarios.

\subsubsection{Baseline Scenario}

In baseline scenario, the simulation time length is set to be 4 hours in total, and a demand profile is constructed with the second hour as the peak demand hour.

Heat map is used in this research to show the temporal-spatial speed profile of the I-10 freeway corridor in the case study network. The $\mathrm{X}$ axis stands for the time, and the $\mathrm{Y}$ axis represents the physical road segment along the corridor, i.e. different road segments are sorted according to their distances away from the corridor starting point. The color in the heat map describes the congestion levels in the traffic network, with blue as free flow condition and red as severely congested. From Figure 3, we can find in the baseline scenario result, that the 
congestion starts from the $2^{\text {nd }}$ hour and lasts 1 -2 hours depending upon the locations, then the network cools down and the traffic becomes free flowing again at the end of simulation.

Some other detailed numbers of interest in the baseline scenario result are:

- The total system travel time in the whole simulation period is 131,639 hours

- Total number of drivers being simulated in this network is 166,634

\subsubsection{Scenario 1 Case study}

\subsubsection{Traffic congestion alleviation}

The left side of Figure 4 and Figure 5 shows the heat map on the freeway for the baseline scenario, and the right side shows the heat map for scenario 1 after the behavior change. It can be observed from the heat maps on the right side that the color of the congested area becomes lighter and the size of the colored area also shrinks, which represents the result that traffic congestion along the freeway corridor has been alleviated noticeably.

\subsubsection{Peak hour demand reduction}

Further analysis of the dataset reveals more in-depth insight into the result. The first observation is that, compared with the baseline scenario, the traffic demand in the peak hour is reduced by 8.4\% in the case study result. Next, those travelers who changed their travel behavior are divided further into several categories depending on their behavior change. Figure 6 shows the number of travelers from different categories.

Among all travelers in the network, $4.3 \%$ travelers changed their departure time but stayed on the same route. For those travelers, 3.7\% of them chose to leave earlier than they used to, and the other $0.6 \%$ postponed their trip for a later time. Only a small portion of travelers chose to take a different route but leave at exactly the same time. The number of travelers who 
not only changed their departure time but also travelled on a route that is different from their previous path accounts for 3.9\% of the whole population.

\subsubsection{Travel time saving}

At the system level, it was found that the total system travel time decreases by $13.9 \%$, dropping from 131,639 to 113,384 hours. The total travel time saving after the behavior change is 18,255 hours.

At the individual driver level, to illustrate the travel time saving benefits, we randomly selected 200 drivers among all 13,688 travelers who changed their travel behavior, and visualized travel time comparison before and after the behavioral changes in Figure 7. We can see that majority of them are able to gain travel time saving due to their behavior changes.

In fact, if we further look into the travel time saving for the whole 13,688 drivers that had various degrees of behavior changes, and divide the travelers into several categories, we can find out that:

- Group 1- travelers who changed their departure time but stayed on the same route can reduce their own travel time by 20.9 min on average

- Group 2 - travelers who changed the route they took but not the departure time can reduce their own travel time by 11.9 min on average.

- Group 3 - travelers who changed both departure time and their route choice can reduce their own travel time by 18.3 min on average.

- Group 4 - other travelers who did not make any changes to either departure time or route choice can benefit with a 4.0 min travel time reduction, although they did not do anything to contribute to the traffic reduction. 


\subsubsection{Monetary saving and cost}

If we translate the travel time saving into monetary value, the saving brought about by the small group of users' behavior change can be significantly huge. The 2011 Annual Urban Mobility report produced by TTI estimated the congestion cost to be $16.79 \$$ per hour of person travel (TTI 2011). If we use that recommended value, the total annual monetary saving will be:

$$
(131,639-113,384) * 2 \text { peak hours/day } * 16.79 \$ / \text { hour } * 260 \text { workdays } / \text { year }=\$ 159 \text { million } / \text { year }
$$

The cost involved in this system varies and depends on the specific strategy to be used to induce the change in travel behavior, but generally speaking it will be relatively cheaper. For example, in the Spitsmijden experiment in Europe (Knockaert, Bliemer et al. 2007), the cost of persuading travelers to make behavior changes is between 3.99\$ per hour to leave earlier and $4.24 \$$ per hour to leave later, which translates to a cost of $\$ 7.4$ million / year.

If we let $\mu 1$ to denote the number of people who shift to an earlier departure time, and let $\quad \mu 2$ denote the number of people who shift to a later departure time, the total cost can be calculated as:

$(\mu 1 * 4.24 \$ /$ hour $+\mu 2 * 3.99 \$ /$ hour $) * 15 \mathrm{~min} /(60 \mathrm{~min} /$ hour $) * 2($ peak hours $) /$ day $* 260$ weekdays $/$.

\section{¿7.4 million/ year}

A similar experiment was also carried out in the US and the cost involved to persuade people to make travel behavior changes is 13.33 \$/hour for leaving earlier and $12.62 \$$ for leaving later (Leblanc and Walker 2013), which gives us $\$ 23.4$ million in total cost:

$\mu 1 * 13.33 \$$ / hour $+\mu 2 * 12.62 \$ /$ hour $i * 15 \mathrm{~min} /(60 \mathrm{~min} /$ hour $) * 2($ peak hours $) /$ day $* 260$ weekdays

\section{¿23.4 million/year}


Compared with the total monetary saving, relatively lower cost can be computed from both research and yields a good Return on Investment (ROI), which indicates the proposed framework is able to reduce the traffic congestion greatly and save a huge amount of money with relative low cost.

\subsubsection{Multi-scenario runs}

\subsubsection{Congestion reduction analysis}

Figure 8 and Figure 9 below show the heat map representing the traffic condition along the I-10 corridor. The scenarios from left to right are: Baseline scenario, SC1, SC3, SC6, SC7 respectively. We can tell from the diagrams that with more travelers willing to change their travel behavior and the more flexibility they possessed, the colored area becomes smaller and the color of the diagram gets lighter as well, which indicates the congestion in the network is significantly alleviated. 


\subsubsection{Travel time saving}

The total travel time savings under different circumstances are also analyzed. We can observe from Figure 10 that there is a significant travel time saving when more travelers are willing to make changes or shift departure time to a larger degree. With more travelers having flexibility regarding their travel, the total benefit the system can get is also increasing.

An interesting observation is the travel time saving in SC1 $(10 \%+15 \mathrm{~min}$ shift $)$ and SC6 $(20 \%+120$ min shift) combined is greater than the travel time saving in SC7 $(30 \%+120 \mathrm{~min}$ shift), i.e., two separate small scale travel behavior changes combined can have larger benefit than one large scale travel behavior change alone, which indicates the marginal system benefit is the highest when travelers start to change their behavior, and decreases when more behavior changes are made.

\subsection{Case study 2 - CAMPO network}

\subsubsection{Background}

This case study to illustrate system performance and behavior changes of the proposed SO model is part of the report ( scenario (SC2) as supplemental analysis (SC2d). Figure 11 shows the overview of the CAMPO network being analyzed in this section, the resulting network includes 10295 nodes, 21368 links and 1462 zones.

Table 1 summarizes the initial scenarios considered in the report. The above proposed behaviorally-induced System Optimal Approach is listed as part of the Technology Strategy that was built off Scenario 2 (SC2) as supplemental study as Scenario 2d (SC2d). Several levels of driver market penetration of the SO routing application were tested (5\%, 10\%, and 20\%), along 
with several levels of allowable flexibility $(15,30$, and 60 minutes) to vary departure time from that specified in the original origin-destination trip table used for Scenario 0, the base case.

\subsubsection{Travel time saving capability}

To test the travel time saving capability of the proposed methodology, the parameters below were used. The result shows the proposed approach is able to save 215,900 hours travel time per day for the system as a whole, and is one of most efficient approaches to reduce traffic congestion.

- SO Routing used only during peak period.

- $20 \%$ driver market share.

- 60-minute maximum flexibility that drivers are allowed to deviate from their original departure time.

\subsubsection{Technical Assessment}

Figure 12 compares Scenario 2d assuming the SO routing technology to Scenario 0 on IH 35 corridor. As shown, there is a noticeable improvement in both the northbound and southbound directions under Scenario 2d. It demonstrates the potential of an existing application for providing measurable impact to reduce IH 35 general purpose lane congestion, even under the extremely congested circumstances projected for the year 2035.

\subsubsection{Technology Strategy Sensitivity Testing}

Table 3 lists various sensitivity tests which demonstrates that with the proposed approach, SO Routing users experience a benefit as a result of using the technology themselves. For example, in scenario SC2k-15-5, where 5\% users follow such ATDM strategy, these users can save 9\% travel time if they switch their departure time, compared with $1 \%$ saving only for the other drivers who does not make any changes. In addition, it was also demonstrated that as more users 
participate in using the technology and being more flexible with regard to the departure, more benefit in terms of travel time saving can be observed. For example, when comparing scenario SC2k-15-5 where only 5\% travelers are willing to change departure time as much as 15 minutes, with scenario SC2k-30-10 where $10 \%$ travelers are willing to change departure time as much as 30 minutes, the later scenario is able to save travels more travel time. Namely, for the drivers who changed their behavior, they can save $18.2 \%$ travel time instead of previous $9.0 \%$, and for the travelers who do not change behavior, they can save $4.0 \%$ compared to previous $1.0 \%$.

\section{CONCLUSIONS AND FUTURE RESEARCH}

This paper documents the research effort in developing a behaviorally induced, system optimal demand management model to improve the system performance towards the system optimal condition. The goal of this model is to at the system level, further improve traffic condition towards system optimal through incremental routing. The outcome of this study shows that our proposed non-construction required modelling framework is promising for improving network traffic conditions towards SO, which results in a vast amount of travel time saving and economic savings with relatively low cost, and the traffic condition along the major corridors can also be observed with significant improvements. In addition, it’s also observed that with more drivers willing to change their travel behavior by changing departure time, or the route they take, the more travel time saving can be observed. It is demonstrated that the incremental routing mechanism in this model is also able to avoid the commonly seen herding effects, and this lowcost non-construction type of demand management strategy is able to effectively alleviate the traffic congestion. 
As for the future research, how to refine the marginal cost calculation approach and make it more accurate is certainly one important aspect to work on, although it's not the focus of this paper at this moment or the original contribution to claim. In addition, the computational efficiency of this model can be further tested and improved. Currently the computation for the whole region with several hundred thousand drivers and 24-hour simulation period takes about an hour, which is not bad at all for a mesoscopic DTA model, but could be further improved for a real time online system.

\section{REFERENCES}

Alibabai, H. and H. S. Mahmassani (2012). "Perturbation Analysis Approach to the Evaluation of Simulated Path Travel Time Marginals: Application to System Optimal Dynamic Network Assignment " Transportation Research Board.

Antoniou, C., A. Polydoropoulou, et al. (2015). "Advanced Traveler Information Systems: Behavioral Responses to Mobile Applications for Transportation." Journal of Intelligent Transportation Systems 19(2): 107-108.

Bernstein, D., T. L. Friesz, et al. (1993). A variational control formulation of the simultaneous route and departure-time choice equilibrium problem. 12th International Symposium on Transportation and Traffic Theory, New York.

Bifulco, G. N., G. E. Cantarella, et al. (2014). "Design of Signal Setting and Advanced Traveler Information Systems." Journal of Intelligent Transportation Systems 18(1): 30-40.

Carey, M. (2012). "Dynamic traffic assignment approximating the kinematic wave model: system optimum, marginal costs, externalities and tolls." Transportation Research Part B: Methodological.

Castillo, E., M. Nogal, et al. (2013). "A Model for Continuous Dynamic Network Loading Problem with Different Overtaking Class Users." Journal of Intelligent Transportation Systems 17(4): 328-350.

Chiu, Y.-C., E. Nava, et al. (2011). "Dynust User's Mannual." http://dynust.net/wikibin/doku.php.

Chiu, Y.-C., L. Zhou, et al. (2009). "Development and Calibration of Anisotropic Mesoscopic Simulation Model for Uninterrupted Flow Facilities." Transportation Research Part B: Methodological 44(1): 152-174.

Daganzo, C. F. (1994). "The cell transmission model: a dynamic representation of highway traffic consistent with the hydrodynamic theory." Transportation Research Part B 28 (4): 269-287.

Friesz, T. L., D. Bernstein, et al. (1993). "A Variational Inequality Formulation of the Dynamic Network User Equilibrium Problem." Operations Research 41(1): 179-191.

Gazis, D. C. (1995). "Congestion abatement in its through centralized route allocation." I V H S Journal 2(2): 139-158.

Ghali, M. O. and M. J. Smith (1992). Dynamic Road Pricing and Dynamic Traffic Assignment for Congested Large Networks. 39th North American Regional Science Association International Conference. Chicago, IL. 
Hu, X. (2013). Developing the Analysis Methodology and Platform for Behaviorally Induced System Optimal Traffic Management. Civil Engineering and Engineering Mechanics, University of Arizona. Ph.D.

Jaber, X. and M. O'Mahony (2009). "Mixed Stochastic User Equilibrium Behavior under Traveler Information Provision Services with Heterogeneous Multiclass, Multicriteria Decision Making." Journal of Intelligent Transportation Systems 13(4): 188-198.

Jeff Shelton, Karen Lorenzini, et al. (2013). Establishing Mobility Investment Priorities Under TxDOT Rider 42: Long-Term Central Texas IH 35 Improvement Scenarios. Prepared for Texas Transportation Commission And 83rd Texas Legislature. Austin, TX, Texas A\&M Transportation Institute, The Texas A\&M University System, College Station, Texas

Kachroo, P. and K. Özbay (2006). "Modeling of Network Level System-Optimal Real-Time Dynamic Traffic Routing Problem Using Nonlinear HœFeedback Control Theoretic Approach." Journal of Intelligent Transportation Systems 10(4): 159-171.

Karimi, H. A. and D. Asavasuthirakul (2014). "A Novel Optimal Routing for Navigation Systems/Services Based on Global Navigation Satellite System Quality of Service." Journal of Intelligent Transportation Systems 18(3): 286-298.

Knockaert, J., M. Bliemer, et al. (2007). Experimental design and modelling spitsmijden. B. Spitsmijden, The Hague.

Leblanc, R. and J. L. Walker (2013). Which is the biggest carrot? Comparing non-traditional incentives for demand management. Transportation Research Board, DC.

Lee, S. (1996). A cell transmission based assignment-simulation model for integrated freeway/surface street systems, The Ohio State University.

Liao, C.-H. and C.-W. Chen (2015). "Use of Advanced Traveler Information Systems for Route Choice: Interpretation Based on a Bayesian Model." Journal of Intelligent Transportation Systems 19(3): 316-325.

Mahut, M. (1999). Speed-maximizing car-following models based on safe stopping rules. 78th TRB Annual Meeting. Washington DC.

Mahut, M. (2001). A Discrete Flow Model for Dynamic Network Loading. Operations and Traffic Management, Universite de Montreal.

Mayeres, I., S. Ochelen, et al. (1996). "The marginal external costs of urban transport." Transportation Research Part D: Transport and Environment 1(2): 111-130.

Meng, Q. and H. L. Khoo (2008). "Optimizing Contraflow Scheduling Problem: Model and Algorithm." Journal of Intelligent Transportation Systems 12(3): 126-138.

Mesa-Arango, R. and S. V. Ukkusuri (2014). "Modeling the Car-Truck Interaction in a System-Optimal Dynamic Traffic Assignment Model." Journal of Intelligent Transportation Systems 18(4): 327338.

Ng, M. and K. Sathasivan (2014). "Probabilistic Modeling of Erroneous Human Response to In-Vehicle Route Guidance Systems: A First Look." Journal of Intelligent Transportation Systems 18(2): 131-137.

Peeta, S. (1994). System optimal dynamic traffic assignment in congested networks with advanced information systems The University of Texas at Austin. DOCTOR OF PHILOSOPHY.

Qian, Z. S. and M. Zhang (2011). "Computing individual path marginal cost in networks with queue spillbacks." Transportation Research Record: 9-18.

Ran, B., D. E. Boyce, et al. (1992). Dynamic user-optimal departure time and route choice model: a bilevel, optimal-control formulation. TIMS/ORSA Joint National Meeting.

Roads, B. o. P. (1964). Traffic Assignment Manual, U.S. Dept. of Commerce, Urban Planning Division, Washington D.C. .

Sheffi, Y. (1985). Urban Transportation Networks: Equilibrium Analysis with Mathematical Programming Methods, Prentice-Hall, NJ.

Shen, W., Y. Nie, et al. (2007). "On Path Marginal Cost Analysis and its Relation to Dynamic SystemOptimal Traffic Assignment." Transportation and Traffic Theory. 
Soriguera, F., J. M. Torné, et al. (2013). "Assessment of Dynamic Speed Limit Management on Metropolitan Freeways." Journal of Intelligent Transportation Systems 17(1): 78-90.

Toledo, T. and R. Beinhaker (2006). "Evaluation of the Potential Benefits of Advanced Traveler Information Systems." Journal of Intelligent Transportation Systems 10(4): 173-183.

Tsirimpa, A. (2015). "Modeling the Impact of Traffic Information Acquisition From Mobile Devices During the Primary Tour of the Day." Journal of Intelligent Transportation Systems 19(2): 125133.

TTI, T. A. M. T. I. (2011). Annual Urban Mobility report

Wie, B.-W., R. L. Tobin, et al. (1995). "A Discrete Time, Nested Cost Operator Approach to the Dynamic Network User Equilibrium Problem." Transportation Science 29(1): 79-92.

Wismans, L., E. V. Berkum, et al. (2013). "Effects of Optimizing Externalities Using Cooperating Dynamic Traffic Management Measures on Network Level." Journal of Intelligent Transportation Systems 17(1): 65-77.

Zhang, X. and G.-L. Chang (2014). "An Optimization Model for Guiding Pedestrian-Vehicle Mixed Flows During an Emergency Evacuation." Journal of Intelligent Transportation Systems 18(3): 273-285.

Zheng, F. and H. Van Zuylen (2014). "The Development and Calibration of a Model for Urban Travel Time Distributions." Journal of Intelligent Transportation Systems 18(1): 81-94. 


\section{FIGURES AND TABLES}

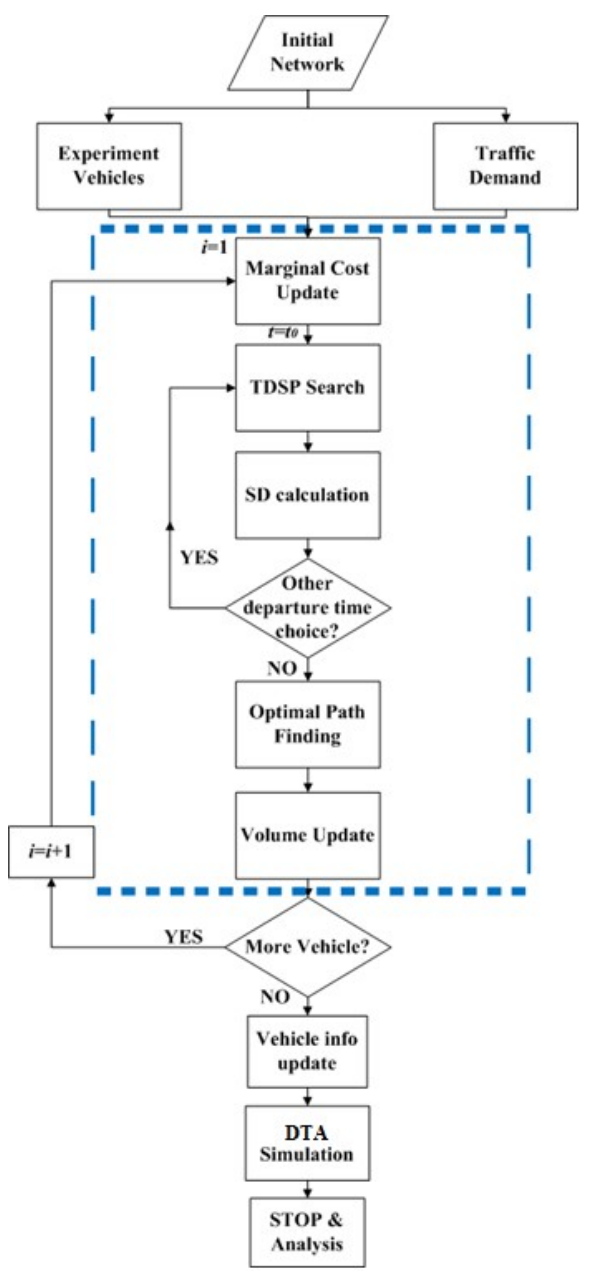

Figure 1: Overall Research Framework 


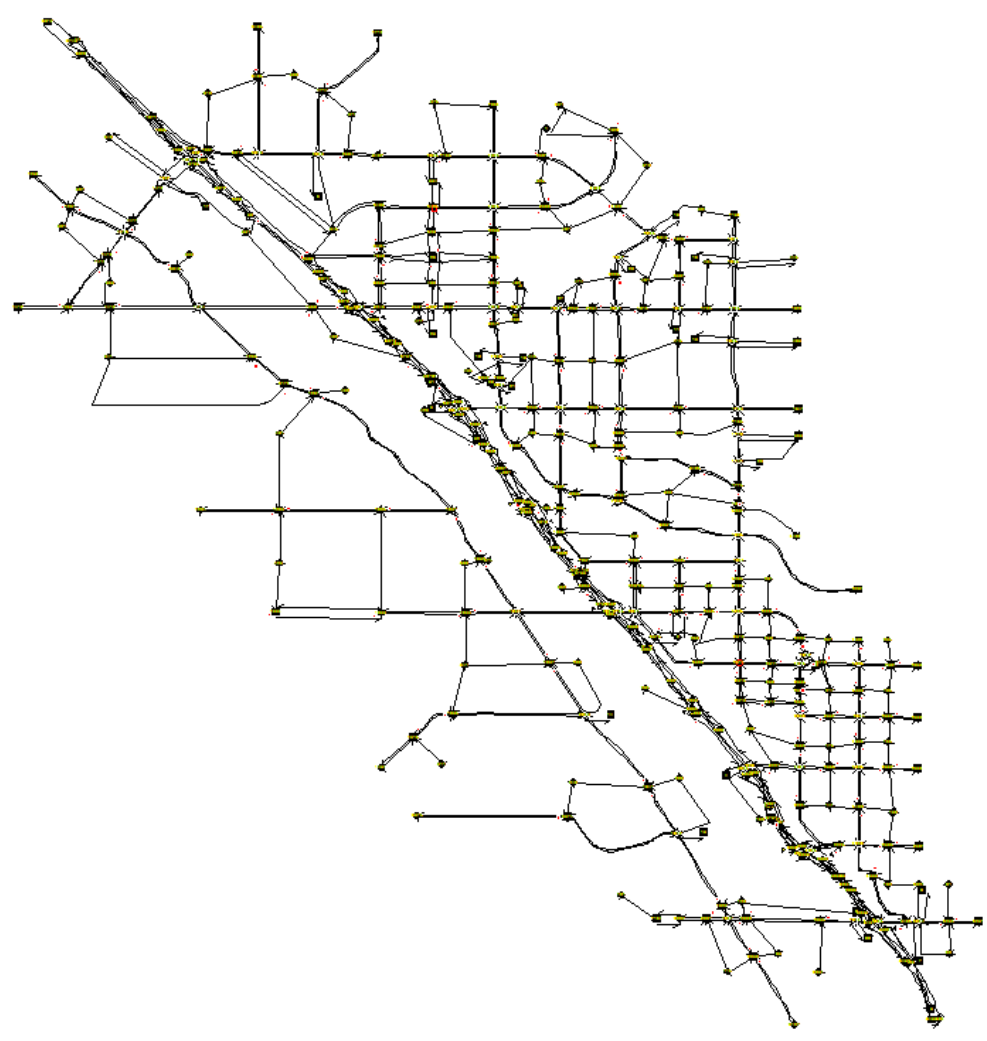

Figure 2: Tucson I-10 Network GUI

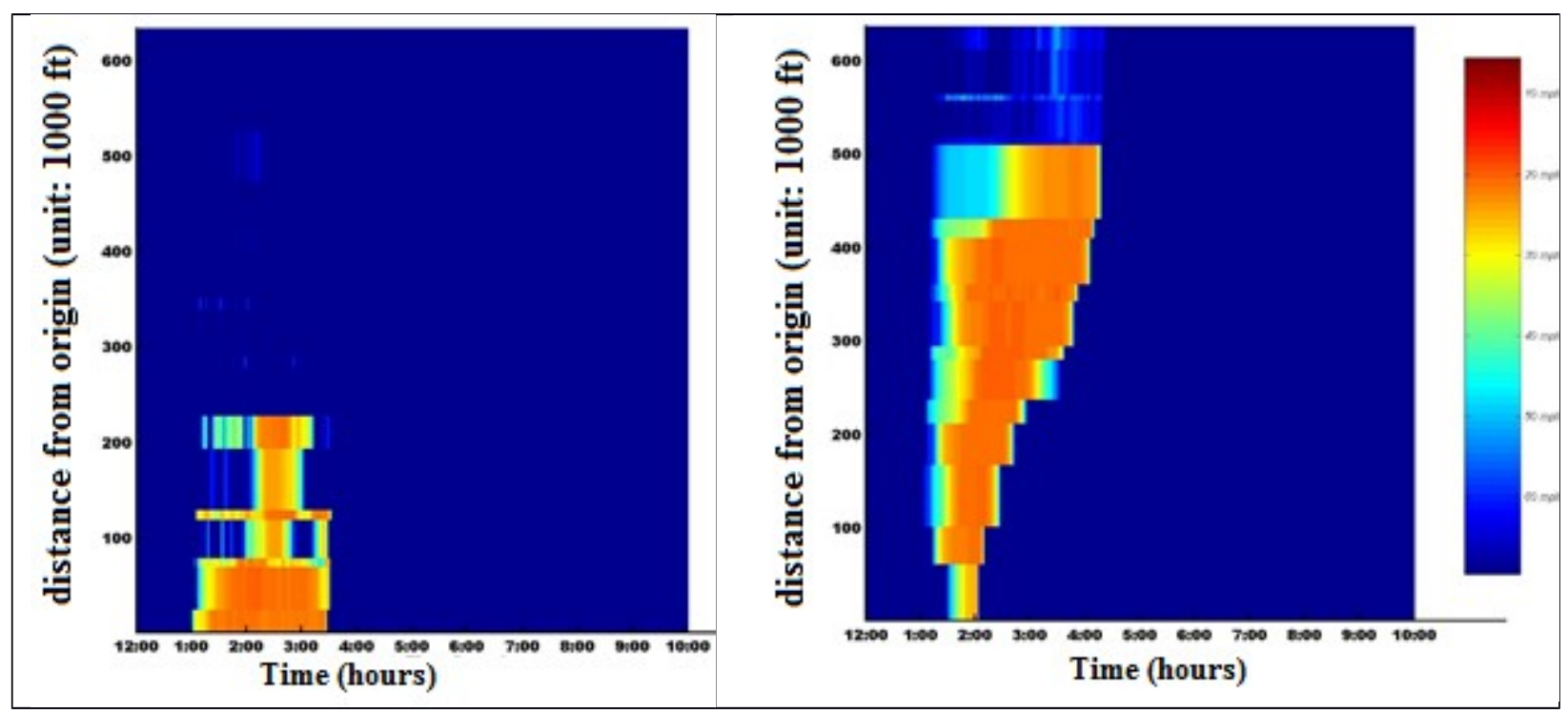

Figure 3: Baseline Scenario Heat Map for I-10 corridor (Left: NB direction, Right: SB) 


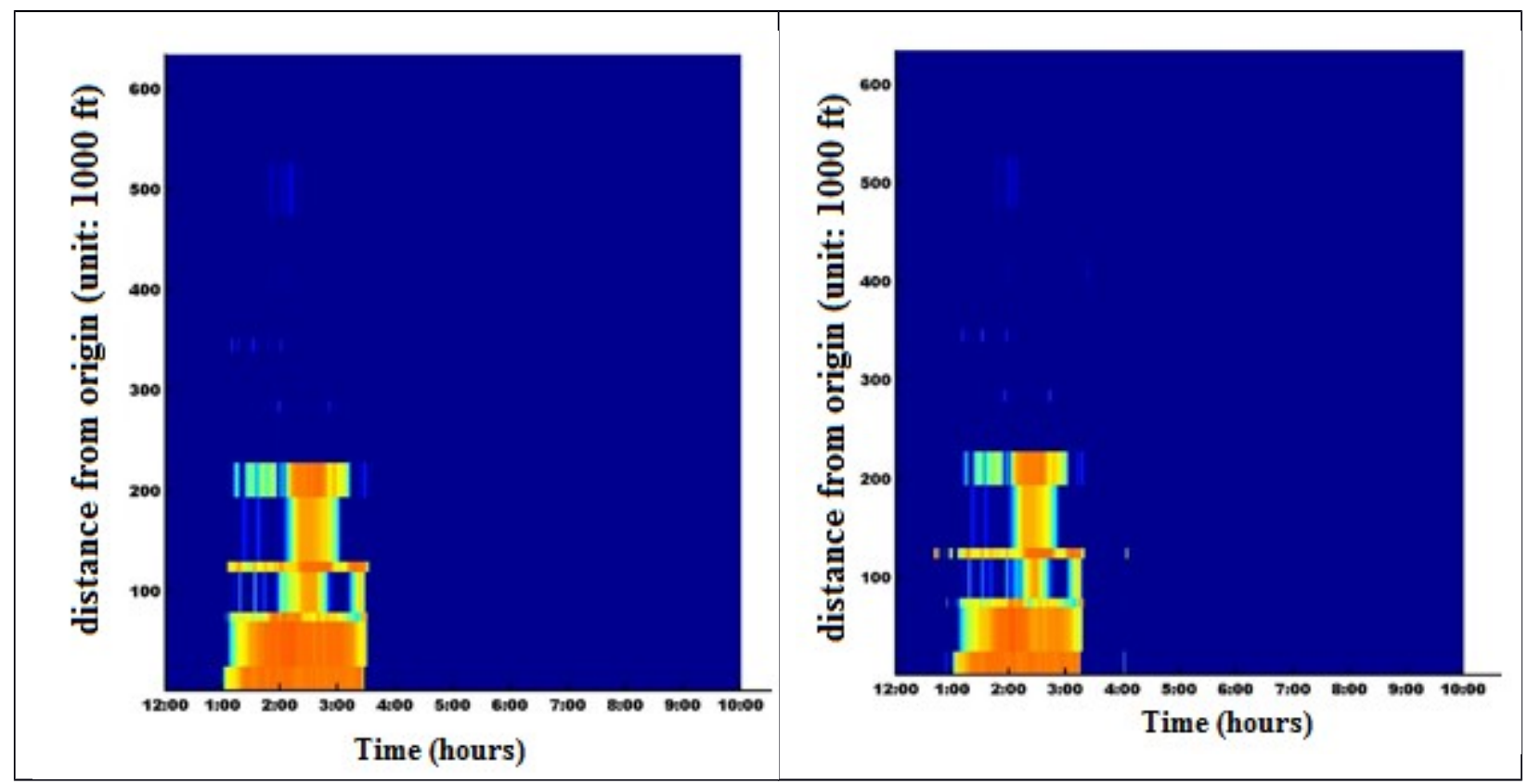

Figure 4: Northbound Scenario Heat Map - Baseline (L) VS Scenario 1 (R)

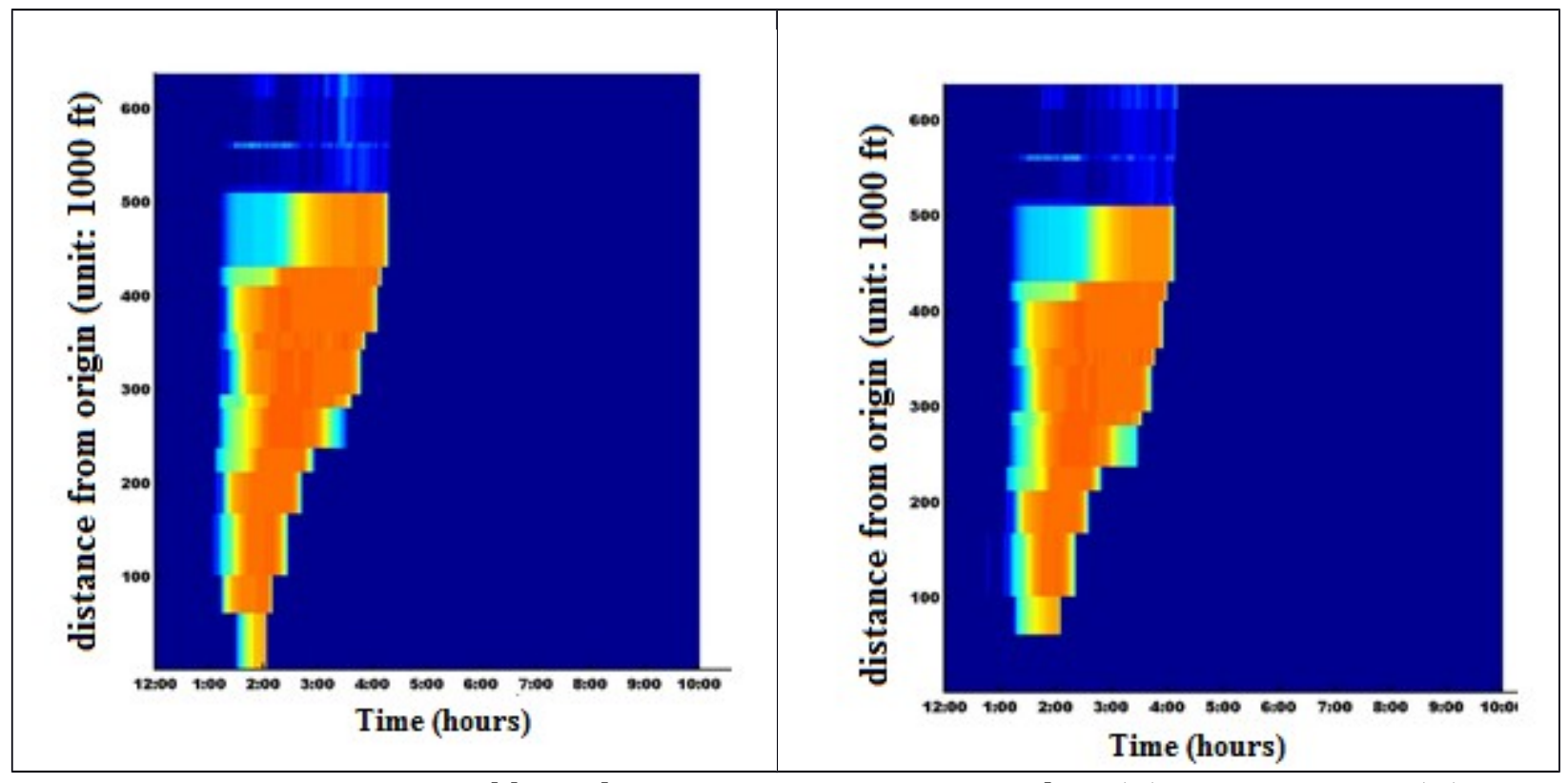

Figure 5: Southbound Scenario Heat Map - Baseline (L) VS Scenario 1 (R) 


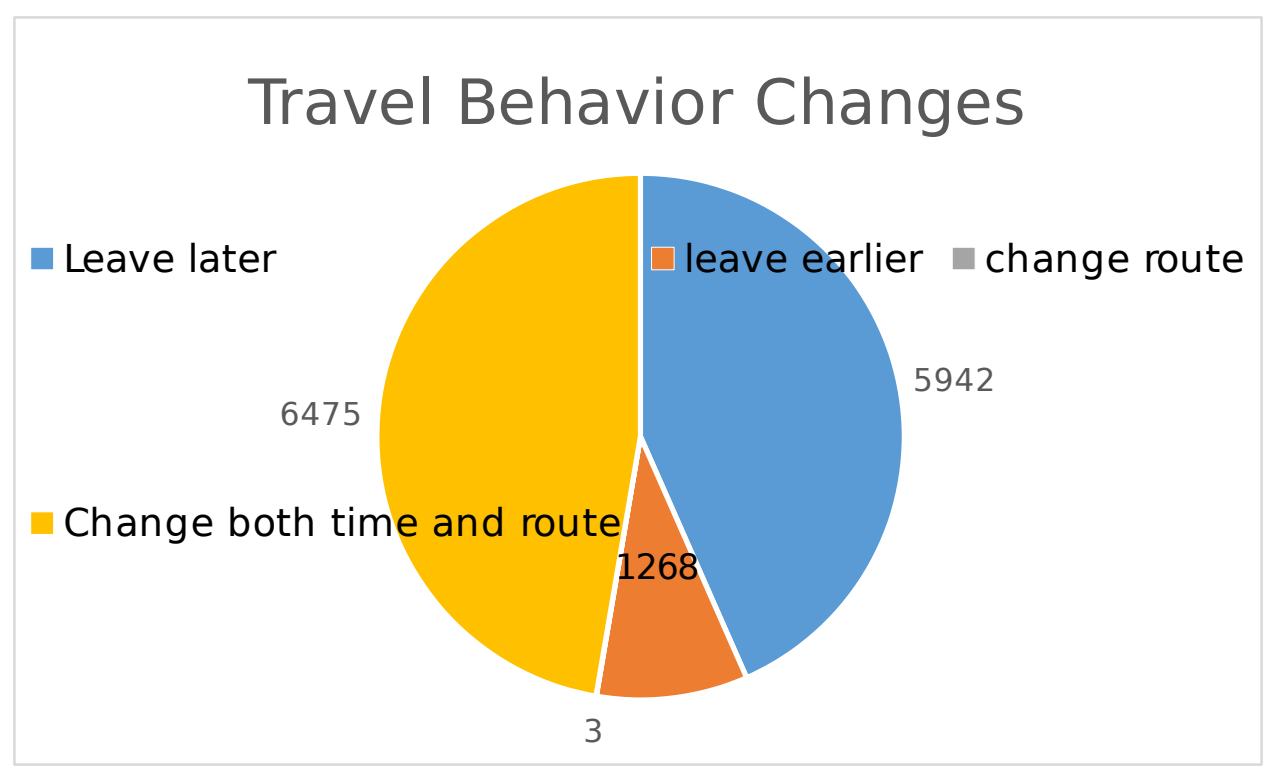

Figure 6: Travel behavior changes in Scenario 1

Travel time comparison before and after the behavior change

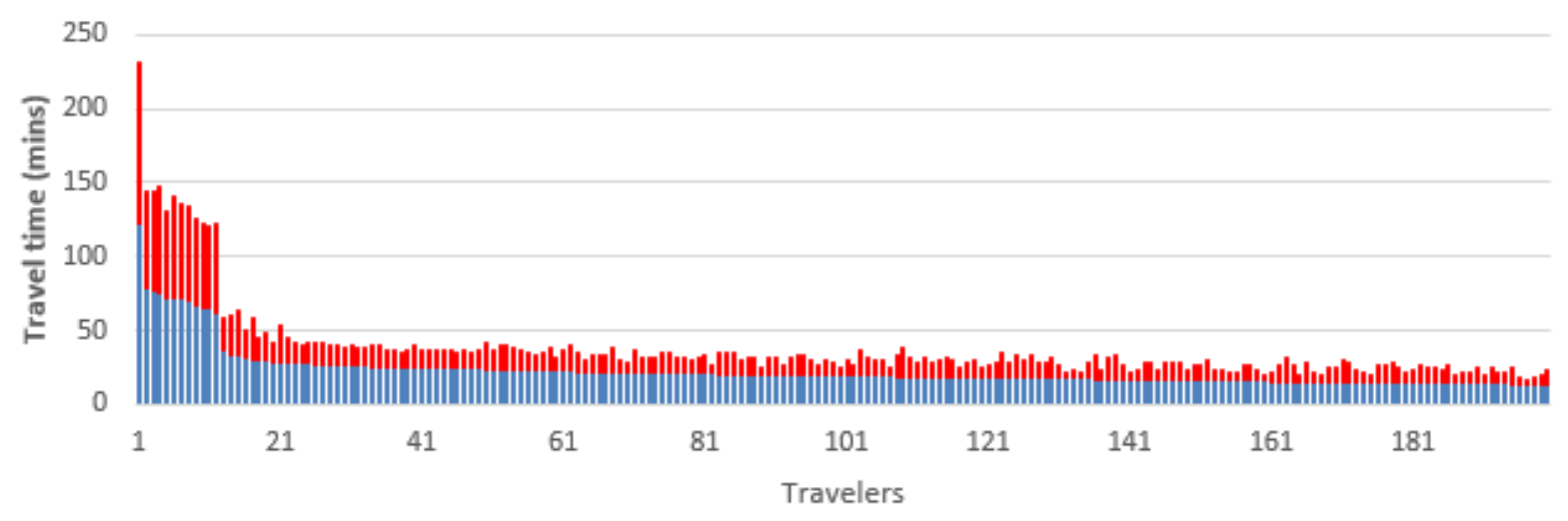

a travel time before behavior changes $\quad$ travel time after behavior changes

Figure 7: Travel time comparison before and after behavior change 

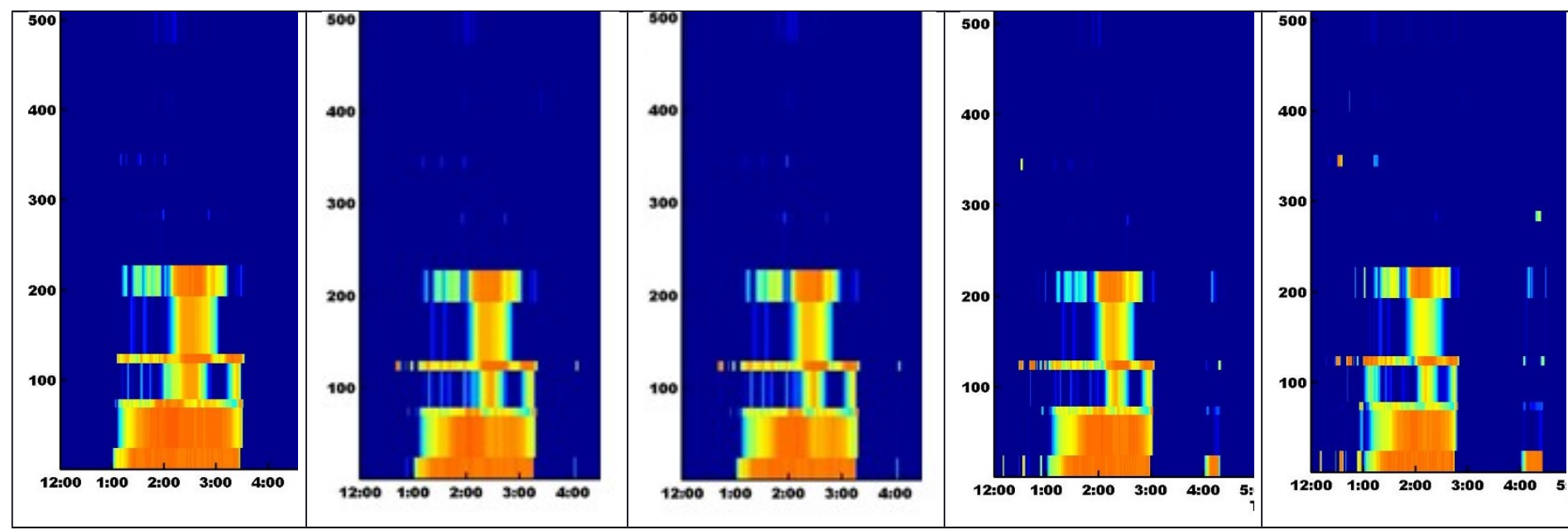

Figure 8: Changes of heat map with behavior change combinations - I-10 NB
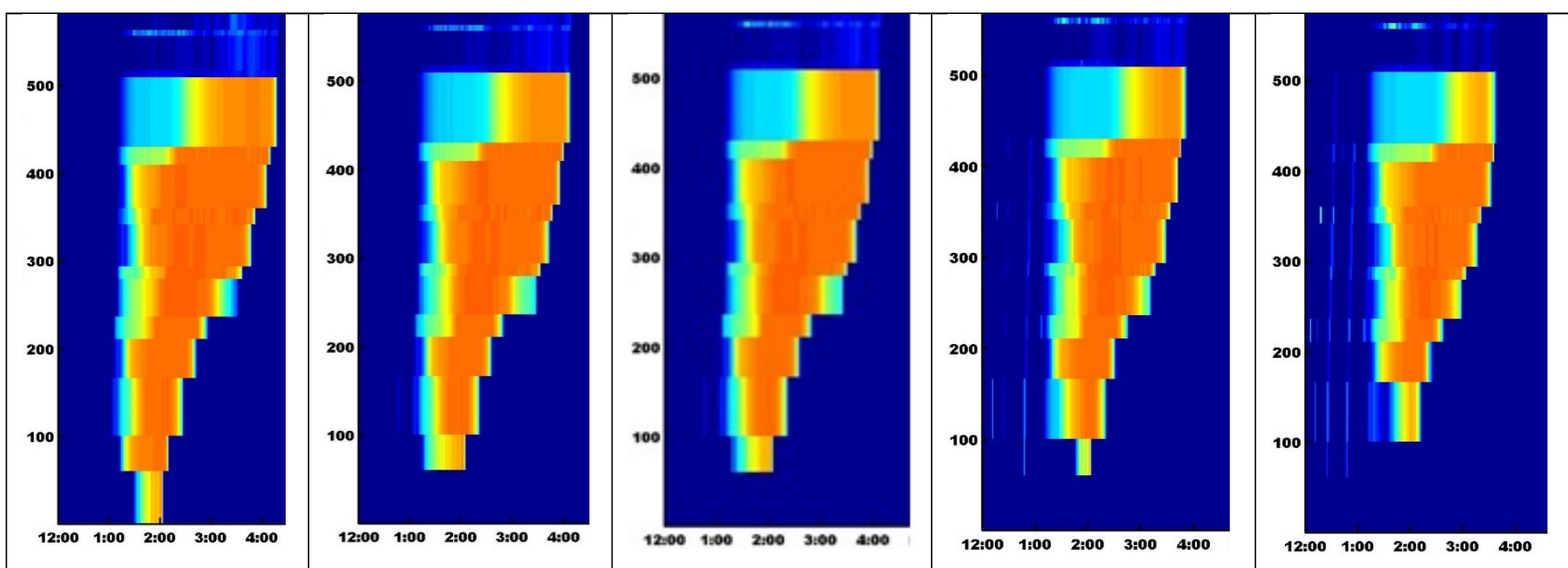

Figure 9: Changes of heat map with behavior change combinations - I-10 SB 


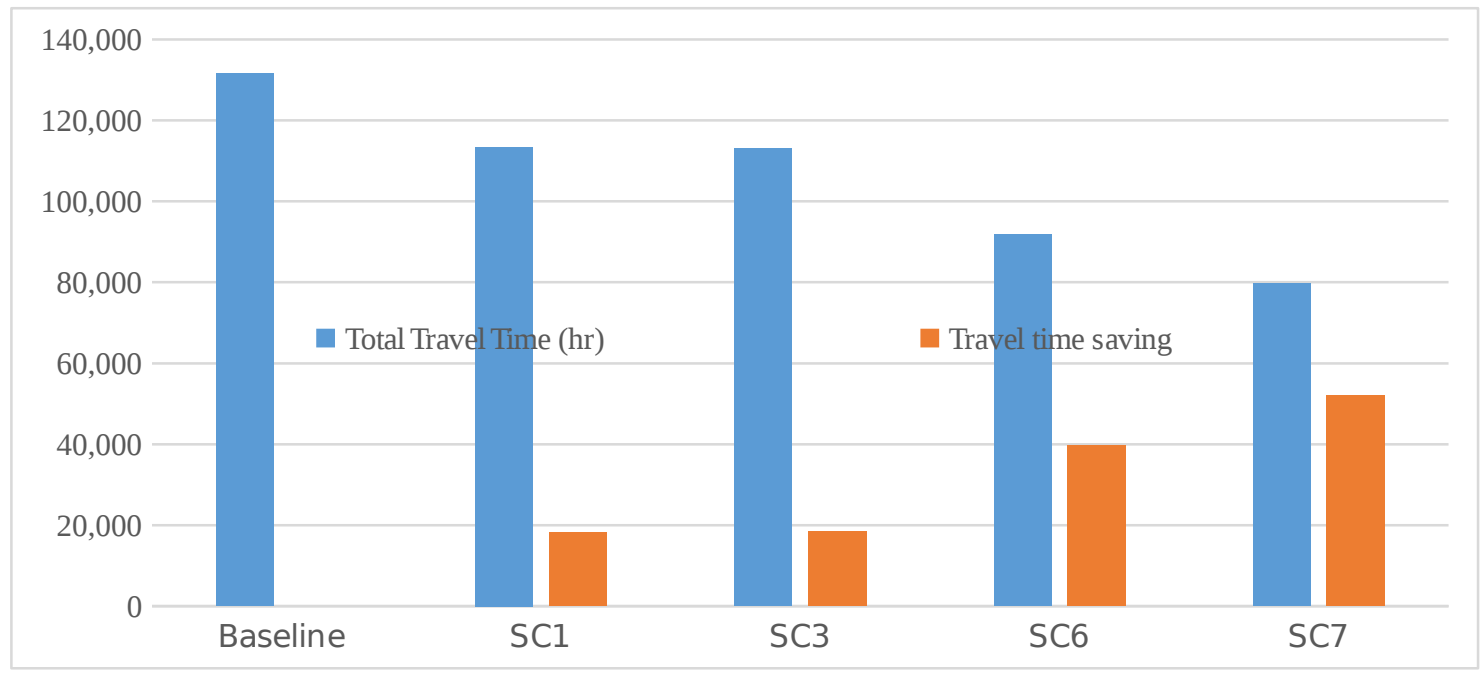

Figure 10: Total travel time changes with behavior change combinations 


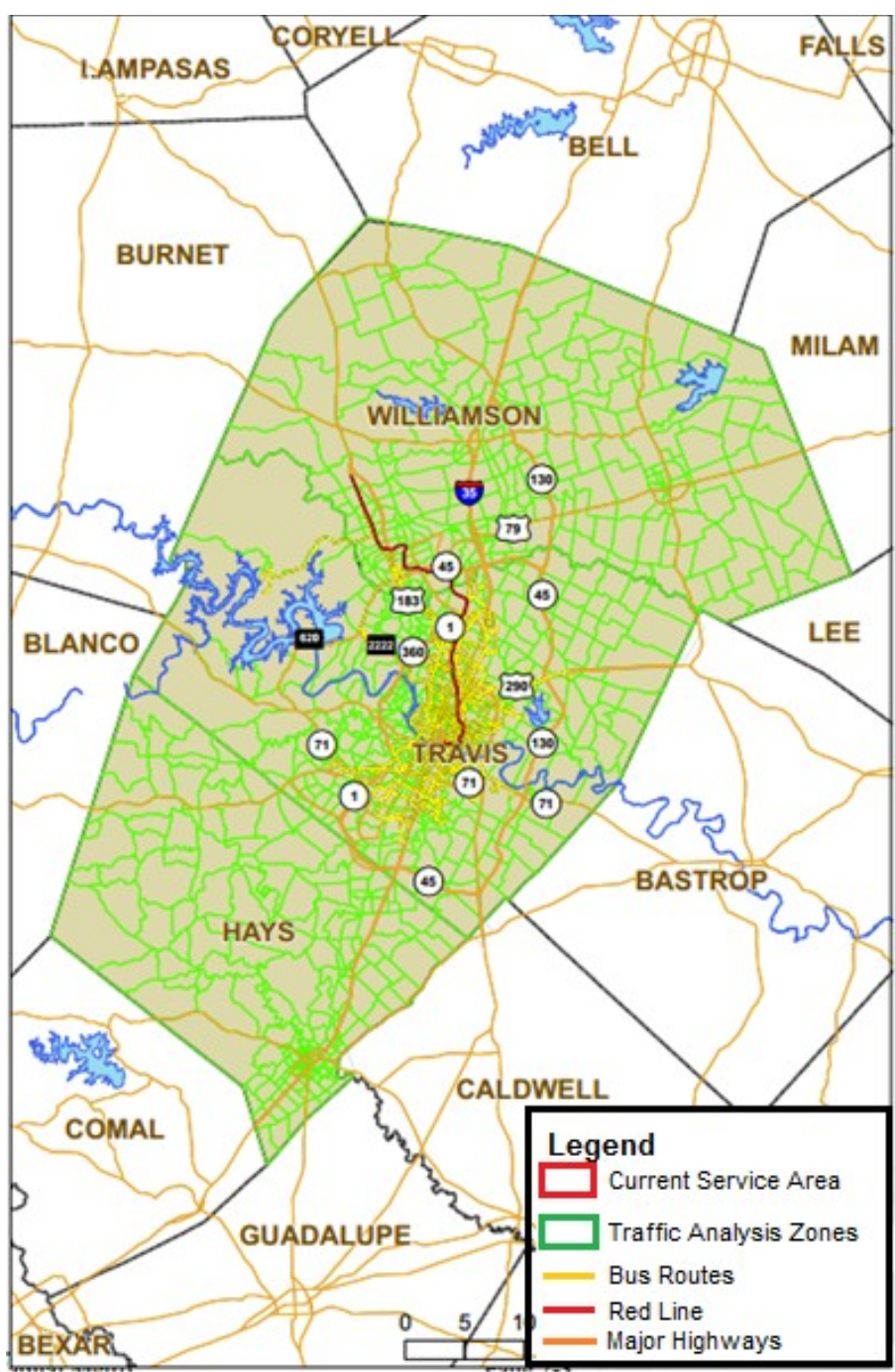

Figure 11: CAMPO network overview 


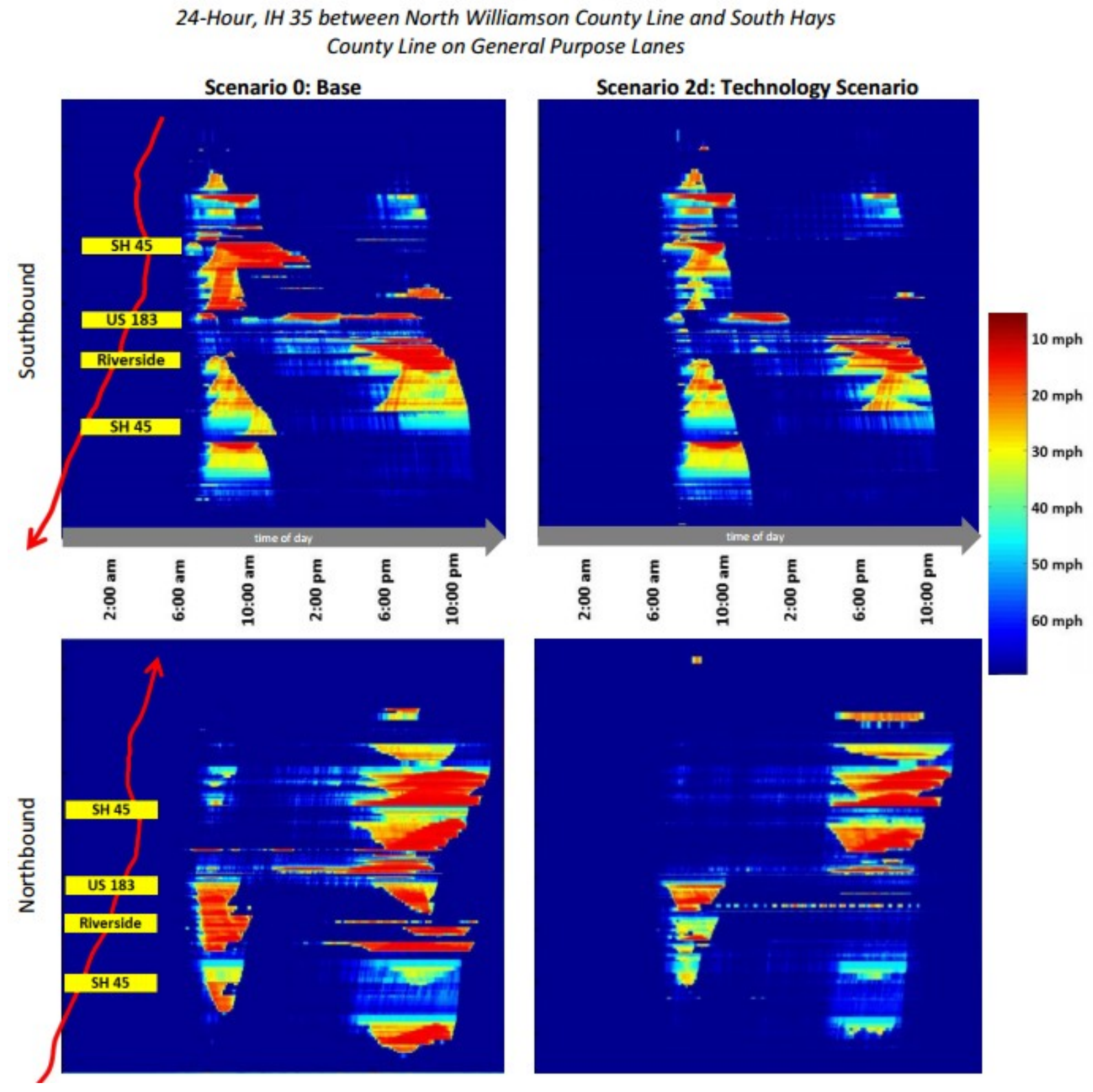

Figure 12: Scenario 2d Heat Diagram Comparison to Scenario 0 
Table 1: List of scenarios tested

\begin{tabular}{|c|c|c|}
\hline Scenario 0 & Base Case & $\begin{array}{l}\text { The } 2035 \text { CAMPO plan-adopted roads and transit } \\
\text { network. Scenario } 0 \text { includes no additional auto or truck } \\
\text { vehicle capacity along IH } 35 \text { between SH } 45 \text { North and } \\
\text { SH } 45 \text { South, which is consistent with the current } \\
\text { CAMPO-adopted plan. }\end{array}$ \\
\hline Scenario 1 & HOV Lanes & $\begin{array}{l}\text { One express lane added to IH } 35 \text { in each direction, HOV } \\
3+\text { and bus transit access only, configuration and access } \\
\text { according to the current City of Austin study between } \\
51 \text { st Street and William Cannon, concept extended to SH } \\
45 \text { North and South. }\end{array}$ \\
\hline Scenario 2 & Express Lanes & $\begin{array}{l}\text { Same as Scenario 1, but allow HOV2 and SOV vehicles } \\
\text { paying an auto toll rate and truck vehicles paying a truck } \\
\text { toll rate. Congestion on these lanes is "managed" by } \\
\text { allowing the toll rate to vary dynamically throughout the } \\
\text { day in order to maintain vehicle flow. }\end{array}$ \\
\hline Scenario 3 & $\begin{array}{l}\text { System-Wide } \\
\text { Dynamic } \\
\text { Pricing }\end{array}$ & $\begin{array}{l}\text { Same as Scenario 2, but allow toll rates to vary } \\
\text { dynamically for IH } 35 \text { and other north-to-south tolled } \\
\text { facilities in the CAMPO 2035-adopted plan system, } \\
\text { specifically SH 130, SH } 45 \text { Southeast, US } 183 \text { South } \\
\text { tolled main lanes, and tolled express lanes along Loop } 1 \\
\text { (MoPac). }\end{array}$ \\
\hline
\end{tabular}




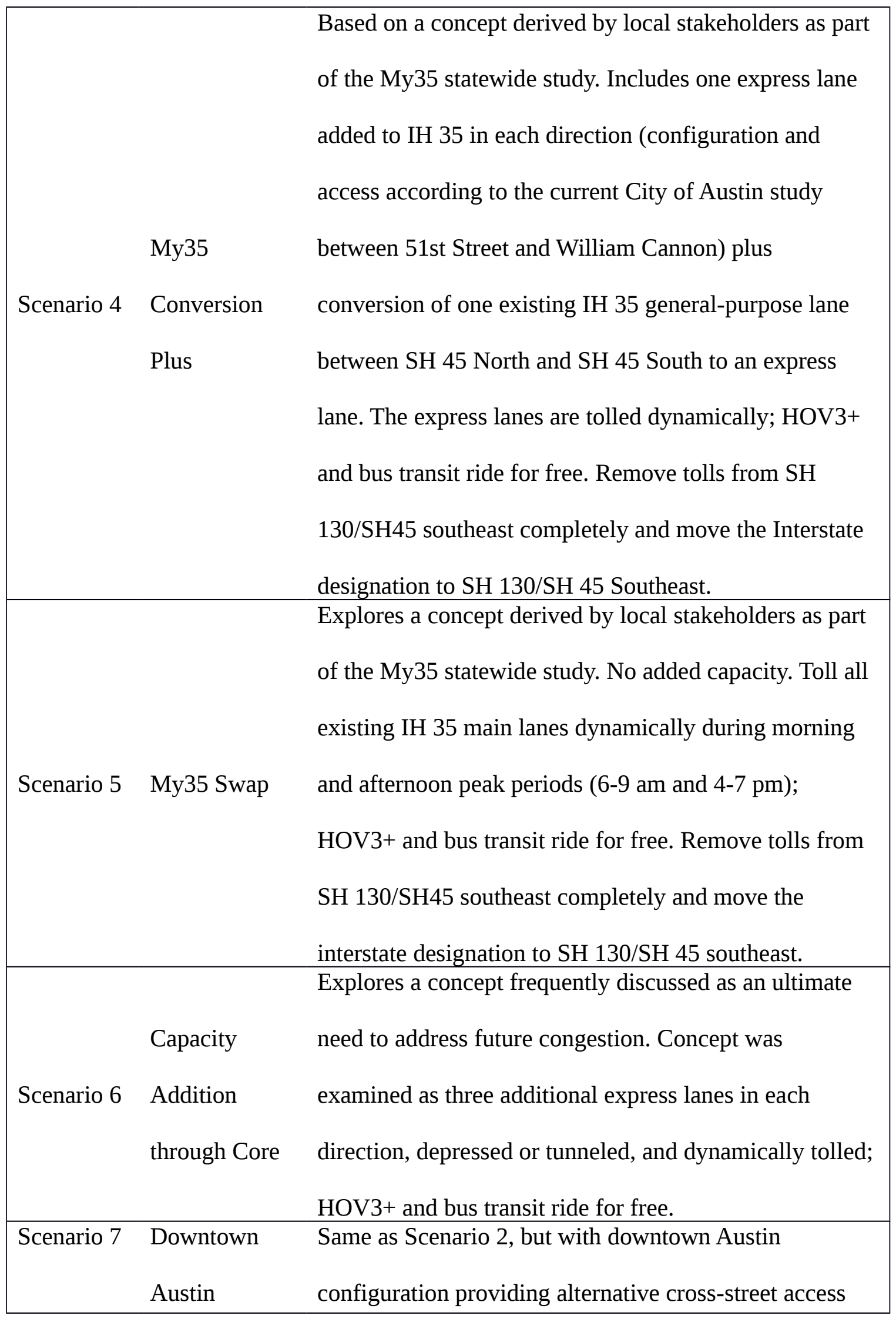


Alternative and separation of through traffic and downtown traffic.

Table 2: Travel time saving analysis

\begin{tabular}{|c|c|c|c|c|c|c|c|c|c|}
\hline ID & SC0 & SC1 & SC2 & SC3 & SC4 & SC5 & SC6 & SC7 & SC2d \\
\hline Scenarios & Base & $\begin{array}{l}\text { HOV } \\
\text { Lanes }\end{array}$ & $\begin{array}{l}\text { Express } \\
\text { Lanes }\end{array}$ & $\begin{array}{l}\text { System- } \\
\text { wide } \\
\text { Dynami } \\
\text { c Pricing }\end{array}$ & $\begin{array}{l}\text { My35 } \\
\text { Convers } \\
\text { ion Plus }\end{array}$ & $\begin{array}{l}\text { My35 } \\
\text { Swap }\end{array}$ & $\begin{array}{l}\text { Capacity } \\
\text { Addition } \\
\text { through } \\
\text { Core }\end{array}$ & $\begin{array}{l}\text { Downtown } \\
\text { Austin } \\
\text { Alternative }\end{array}$ & $\begin{array}{l}\text { Proposed } \\
\text { Model - } \\
\text { Smartrek } \\
\text { Technolo } \\
\text { gy }\end{array}$ \\
\hline $\begin{array}{l}\text { Person- } \\
\text { Hours } \\
\text { Traveled }\end{array}$ & $\begin{array}{l}3.88 \\
\text { M }\end{array}$ & $\begin{array}{l}3.83 \\
\mathrm{M}\end{array}$ & $3.69 \mathrm{M}$ & $3.85 \mathrm{M}$ & $3.86 \mathrm{M}$ & $3.96 \mathrm{M}$ & $3.91 \mathrm{M}$ & $3.69 \mathrm{M}$ & $3.66 \mathrm{M}$ \\
\hline
\end{tabular}

Table 3: Technology Strategy Sensitivity Testing

\begin{tabular}{|c|c|c|c|c|c|c|}
\hline Simulation Period (24hr) & $\mathrm{SC} 2$ & $\begin{array}{c}\text { SC2k-15- } \\
5 \\
\end{array}$ & $\begin{array}{c}\text { SC2k-30- } \\
10 \\
\end{array}$ & $\begin{array}{c}\text { SC2k-60- } \\
10 \\
\end{array}$ & $\begin{array}{c}\text { SC2k-30- } \\
20 \\
\end{array}$ & $\begin{array}{c}\text { SC2k-60- } \\
20 \\
\end{array}$ \\
\hline $\begin{array}{l}\text { Max Shift Period (+-min) } \\
\text { Smartrek Market Share }\end{array}$ & 0 & 15 & 30 & 60 & 30 & 60 \\
\hline $\begin{array}{l}(\mathrm{AM}+\mathrm{PM}) \\
\text { Smartrek Market Share }\end{array}$ & 0 & $5 \%$ & $10 \%$ & $10 \%$ & $20 \%$ & $20 \%$ \\
\hline$(24 \mathrm{hr})$ & $0.0 \%$ & $2.0 \%$ & $4.1 \%$ & $4.1 \%$ & $8.2 \%$ & $8.2 \%$ \\
\hline Daily Average TT & 21.6 & 21.5 & 21.1 & 20.5 & 20.8 & 20.1 \\
\hline Smartrek Users (\#) & 0 & 180,678 & 361,357 & 361,357 & 722,713 & 722,713 \\
\hline Shift Early (\#) & 0 & 76,447 & 162,892 & 183,581 & 333,018 & 370,433 \\
\hline Shift Late (\#) & 0 & 64,060 & 135699 & 138,429 & 272,965 & 277,578 \\
\hline No Change (\#) & 0 & 40,171 & 62,766 & 39,347 & 116,730 & 74,702 \\
\hline Daily TT Saving (hr) & 0 & 14,337 & 72,092 & 153,890 & 111,911 & 215,925 \\
\hline
\end{tabular}




\begin{tabular}{|c|c|c|c|c|c|c|}
\hline Daily TT Saving (\%) & 0 & $-0.4 \%$ & $-2.3 \%$ & $-4.8 \%$ & $-3.5 \%$ & $-6.8 \%$ \\
\hline \multicolumn{7}{|c|}{ TT for Smartrek users who } \\
\hline shift (min) & 0 & 23.5 & 21.1 & 17.2 & 21.3 & 17.8 \\
\hline Saving & 0 & $9.0 \%$ & $18.2 \%$ & $33.4 \%$ & $17.5 \%$ & $31.2 \%$ \\
\hline \multicolumn{7}{|l|}{ TT for peak hour non } \\
\hline Smartrek users (min) & 0 & 25.6 & 24.8 & 23.7 & 24.2 & 22.7 \\
\hline Saving & 0 & $1.0 \%$ & $4.0 \%$ & $8.0 \%$ & $6.3 \%$ & $12.1 \%$ \\
\hline \multicolumn{7}{|l|}{ Peak Average TT for all } \\
\hline users (min) & 25.8 & 25.4 & 24.4 & 23.1 & 23.6 & 21.7 \\
\hline Saving & 0 & $1.4 \%$ & $5.4 \%$ & $10.5 \%$ & $8.5 \%$ & $15.9 \%$ \\
\hline \multicolumn{7}{|c|}{ Saving Contributed by each } \\
\hline Smartrek Users & 0 & -6.1 & -14.5 & -28.7 & -11.1 & -20.0 \\
\hline \$\$ Annual Saving (\$M) & 0 & 59.6 & 299.9 & 640.2 & 465.5 & 898.2 \\
\hline
\end{tabular}

